\title{
Metastasis-Directed Radiotherapy for Oligoprogressive Castration-Resistant Prostate Cancer Recurrence Revealed by Choline PET/CT
}

\author{
Kazuhiro Kitajima ${ }^{a}$ Shingo Yamamoto ${ }^{b}$ Masayuki Fujiwara ${ }^{a}$ \\ Hitomi Suzuki ${ }^{a}$ Nahomi Yoshimura ${ }^{a}$ Ryo Kunimoto ${ }^{a}$ \\ Hiroyuki Yokoyama $^{a}$ Hisashi Komoto $^{a}$ Yusuke Yamadab \\ Seiji Nagasawa $^{b}$ Akihiro Kanematsu $^{b}$ Ryoong-Jin Oh ${ }^{c}$ \\ Koichiro Yamakadoa \\ aDepartment of Radiology, Hyogo College of Medicine, Nishinomiya, Japan; \\ bepartment of Urology, Hyogo College of Medicine, Nishinomiya, Japan; 'Department of \\ Radiology, Miyakojima iGRT Clinic, Osaka, Japan
}

\section{Keywords}

Castration-resistant prostate cancer · Oligometastasis · Choline PET/CT

\begin{abstract}
We report a 49-year-old male with castration-resistant prostate cancer (CRPC) with oligometastasis diagnosed by ${ }^{11} \mathrm{C}$-choline positron emission tomography-computed tomography (PET/CT) and treated with target radiotherapy. In the diagnosis of CRPC (serum prostate-specific antigen [PSA] level of $6.53 \mathrm{ng} / \mathrm{mL}$ after maximum androgen blockade (MAB) therapy, high-dose brachytherapy, and external beam radiotherapy), ${ }^{11} \mathrm{C}$-choline PET/CT detected one tiny obturator lymph node metastasis which fluorodeoxyglucose PET/CT could not detect. He underwent intensity-modulated radiation therapy and MAB was restarted. The PSA value decreased and reached nadir $(0.091 \mathrm{ng} / \mathrm{mL})$ after 6 months. The time to PSA progression was 10 months. The choline PET/CT finding and the corresponding local treatment could play an important role in the management sequence of oligoprogressive CRPC.
\end{abstract}

\section{Karger"}




\section{Case Reports in Oncology}

\begin{tabular}{l|l}
\hline Case Rep Oncol 2021;14:13-16 \\
\hline DOI: 10.1159/000512068 & $\begin{array}{l}\text { @ 2021 The Author(s). Published by S. Karger AG, Basel } \\
\text { www.karger.com/cro }\end{array}$ \\
\hline
\end{tabular}

Kitajima et al.: Choline PET/CT-Guided Local Treatment of Oligoprogressive CRPC Recurrence

\section{Introduction}

Castration-resistant prostate cancer (CRPC) is considered to be fatal, with the median survival ranging from 9 to 30 months [1]. New treatment strategies for CRPC must be investigated, and locoregional therapy against metastatic prostate cancer has generated great interest [2,3]. The utility of metastasis-directed therapy was shown in a prospective randomized phase 2 trial [4]. For patients with biochemical recurrence and 3 or few metastatic lesions clarified by choline positron emission tomography-computed tomography (PET/CT), metastasis-directed therapy (surgery or stereotactic body radiotherapy) improved androgen deprivation therapy (ADT)-free survival. These findings suggest that locoregional therapy should be considered in prostate cancer with low metastatic burden. Here we present a case of ${ }^{11} \mathrm{C}$-choline PET/CT-guided local radiotherapy in oligoprogressive CRPC recurrence.

\section{Case Report}

One year and 6 months ago, a 49-year-old man with biopsy-proven prostate cancer (Gleason score $4+5$ ), serum prostate-specific antigen (PSA) level of $15.0 \mathrm{ng} / \mathrm{mL}$ and clinical stage of T2N0M0 underwent maximum androgen blockade (MAB) therapy and high-dose brachytherapy ( $110 \mathrm{~Gy}$ ) as initial treatments. One year and 2 months ago, he received external beam radiotherapy (39.6 Gy). The PSA value reached the nadir of $0.053 \mathrm{ng} / \mathrm{mL}$; however, the PSA value gradually increased to $6.53 \mathrm{ng} / \mathrm{mL}$ and CRPC was diagnosed. He underwent fluorodeoxyglucose (FDG) PET/CT and ${ }^{11} \mathrm{C}$-choline PET/CT examination to evaluate the patient's current disease status for restaging. Although FDG PET/CT showed no abnormal FDG uptake in the whole body (Fig. 1a), ${ }^{11} \mathrm{C}$-choline PET/CT showed a tiny left obturator lymph node measuring $8 \mathrm{~mm}$ with abnormal ${ }^{11} \mathrm{C}$-choline uptake (maximum standardized uptake value of

(a)

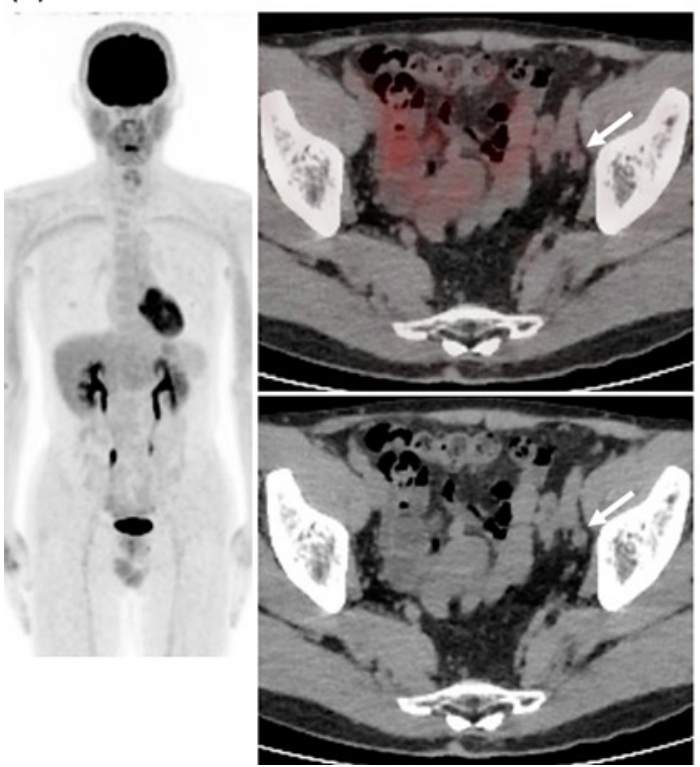

(b)

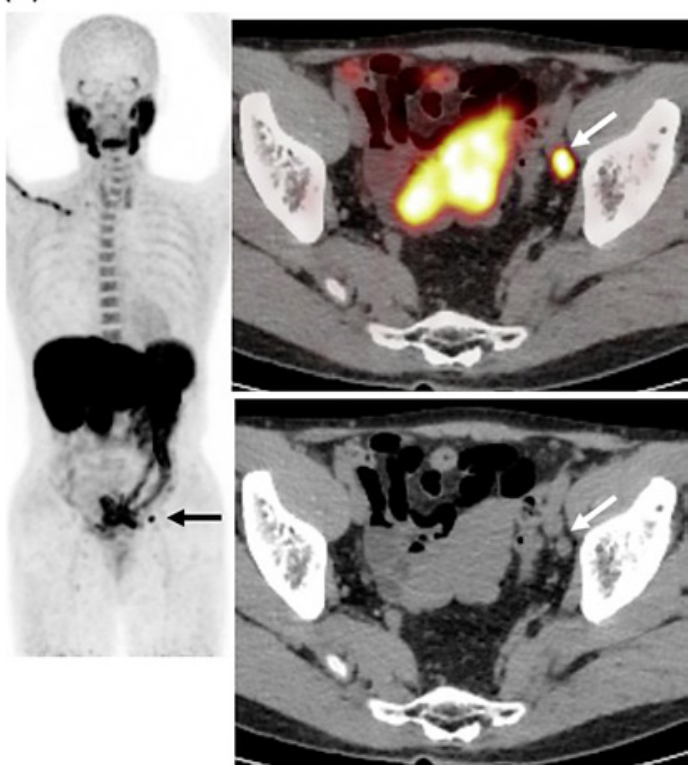

Fig. 1. A 49-year-old man with oligometastasis of CRPC diagnosed by ${ }^{11} \mathrm{C}$-choline PET/CT. a FDG PET/CT showed no abnormal FDG uptake in the whole body. $\mathbf{b}^{11} \mathrm{C}$-choline PET/CT showed a tiny left obturator lymph node measuring $8 \mathrm{~mm}$ with abnormal ${ }^{11} \mathrm{C}$-choline uptake (maximum standardized uptake value of 6.28), suggesting one lymph node metastasis. 
Kitajima et al.: Choline PET/CT-Guided Local Treatment of Oligoprogressive CRPC Recurrence

Fig. 2. A 49-year-old man with ${ }^{11} \mathrm{C}$-choline-PET/CT-proven oligometastatic CRPC treated by IMRT. Dose distribution of intensity-modulated radiation therapy on the radiation therapy planning system. The prescribed radiation dose was 70 Gy for metastatic left obturator lymph node and 52 Gy for left internal and external iliac nodes in 30 fractions.

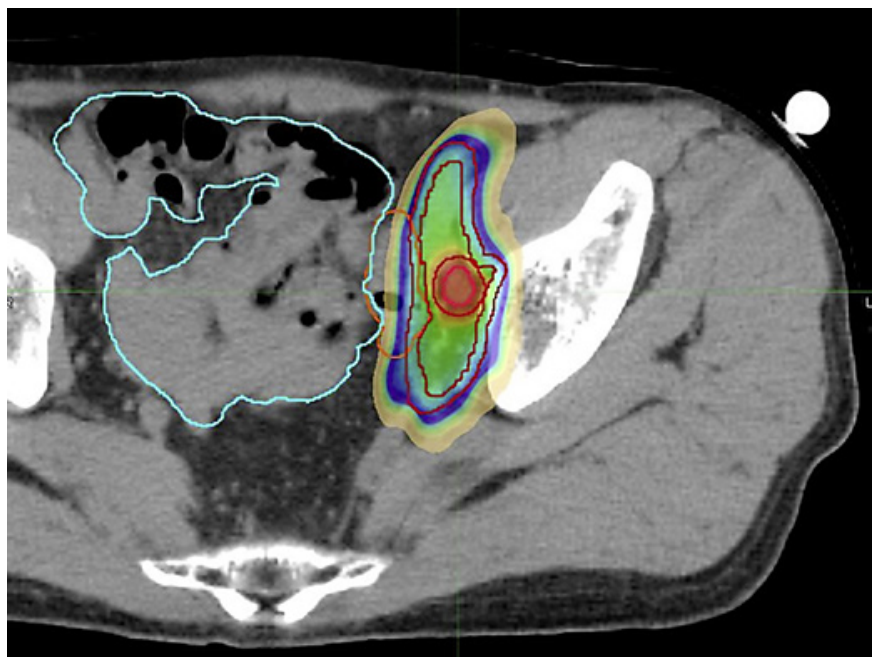

6.28), suggesting one lymph node metastasis (Fig. 1b). Under the diagnosis of oligometastasis, he received intensity-modulated radiation therapy (IMRT) (Fig. 2) and MAB (goserelin acetate and bicalutamide) was restarted. PSA value gradually decreased and reached nadir $(0.091 \mathrm{ng} / \mathrm{mL})$ after 6 months. However, the PSA value increased to $0.24 \mathrm{ng} / \mathrm{mL}$ at 10 months after the start of IMRT and new hormonal therapy (Abiraterone) was started, which improved the PSA level to $0.028 \mathrm{ng} / \mathrm{mL}$ after 7 months.

\section{Discussion}

In recent years, imaging-guided locoregional therapy for oligometastatic CRPC has generated great interest. Several groups have shown the usefulness of choline PET/CT [4-6]. Ost et al. [4] randomly assigned 62 patients with 3 or fewer metastatic lesions on choline PET/CT to two groups (surveillance vs. metastasis-directed therapy including surgery or stereotactive body radiotherapy) and demonstrated that the median $\mathrm{ADT}$-free survival was 13 months $(80 \%$ confidence interval [CI], 12-17 months) for the surveillance group and 21 months (80\% CI, 14-29 months) for the metastasis-directed therapy group (hazard ratio, 0.60 [80\% CI, 0.40-0.90]; $\log$-rank $p=0.11$ ). In a multicenter study of 86 CRPC patients with 1-5 oligoprogressive metastases, defined as progressive disease at bone or nodes levels (detected by means of most choline PET/CT during ADT), Triggiani et al. [5] reported that the median new metastasis-free survival after stereotactive body radiotherapy was 12.3 months (95\% CI 5.5-19.1 months). In a small series of 7 patients with local prostate cancer and/or one or two metastatic lesions detected by choline PET/CT, Nozaki et al. [6] reported that the median progression-free survival after radiotherapy or lymphadenectomy was 8.5 months (range, 2.8-25.3 months).

There have been reports of other imaging modalities. Lohaus et al. [7] reported the first result of ${ }^{67}$ Ga prostate-specific membrane antigen PET-guided local ablative radiation therapy in patients with oligoprogressive CRPC. The time to PSA progression (PSA nadir plus $2 \mathrm{ng} /$ $\mathrm{mL}$ ) of 15 patients with CRPC with 3 or fewer metastases on prostate-specific membrane antigen PET/CT or PET/magnetic resonance imaging (MRI) was 17.9 months. Yoshida et al. [8] reported the first result of whole-body diffusion-weighted MRI-guided progressive sitedirected radiation therapy in patients with oligoprogressive CRPC. The time to PSA progression (PSA nadir plus $2 \mathrm{ng} / \mathrm{mL}$ ) of 23 patients with CRPC with 3 or fewer metastases on whole-body diffusion-weighted MRI was 8.7 months [8]. 


\section{Case Reports in Oncology}

\begin{tabular}{l|l}
\hline Case Rep Oncol 2021;14:13-16 \\
\hline DOI: 10.1159/000512068 & $\begin{array}{l}\text { ○ 2021 The Author(s). Published by S. Karger AG, Basel } \\
\text { www.karger.com/cro }\end{array}$ \\
\hline
\end{tabular}

Kitajima et al.: Choline PET/CT-Guided Local Treatment of Oligoprogressive CRPC Recurrence

\section{Conclusion}

Choline PET/CT finding and the corresponded local treatment could play an important role in the management sequence of oligoprogressive CRPC.

\section{Statement of Ethics}

This report complies with the guidelines for human studies and includes evidence that the research was conducted ethically in accordance with the World Medical Association Declaration of Helsinki. The authors have no ethical conflicts to disclose. Written informed consent was obtained from the patient for publication of this case report and any accompanying images.

\section{Conflict of Interest Statement}

The authors have no conflicts of interest to declare.

\section{Funding Sources}

This work was supported by JSPS KAKENHI grant numbers 19 K08187.

\section{Author Contributions}

Concept and design: K.K., S.Y., M.F., K.Y.; acquisition of data: S.Y., M.F., H.S., N.Y., R.K., H.Y., H.K., Y.Y., S.N., A.K., R.O.; drafting of the manuscript: K.K.; critical revision of the manuscript for important intellectual content: S.Y., M.F., K.Y.. All authors approved the final version of the manuscript.

\section{References}

1 Kriby M, Hirst C, Crawford ED. Characterising the castration-resistant prostate cancer population: a systematic review. Int J Clin Pract. 2011;65:1180-92.

2 Ost P, Jereczek-Fossa BA, As NV, Zilli T, Muacevic A, Olivier K, et al. Progression-free Survival Following Stereotactic Body Radiotherapy for Oligometastatic Prostate Cancer Treatment-naive Recurrence: A Multi-institutional Analysis. Eur Urol. 2016;69(1):9-12.

3 Leyh-Bannurah SR, Gazdovich S, Budäus L, Zaffuto E, Briganti A, Abdollah F, et al. Local Therapy Improves Survival in Metastatic Prostate Cancer. Eur Urol. 2017;72(1):118-24.

4 Ost P, Reynders D, Decaestecker K, Fonteyne V, Lumen N, De Bruycker A, et al. Surveillance or MetastasisDirected Therapy for Oligometastatic Prostate Cancer Recurrence: A Prospective, Randomized, Multicenter Phase II Trial. J Clin Oncol. 2018;36(5):446-53

5 Triggiani L, Mazzola R, Magrini SM, Ingrosso G, Borghetti P, Trippa F, et al. Metastasis-directed stereotactic radiotherapy for oligoprogressive castration-resistant prostate cancer: a multicenter study. World J Urol. 2019;37(12):2631-7.

6 Nozaki K, Kawai T, Fujimura T, Matsui H, Teshima T, Oshina T, et al. Carbon 11-choline positron emission tomography/computed tomography and palliative local therapy for castration-resistant prostate cancer. Int Urol Nephrol. 2019;51(10):1763-9.

7 Lohaus F, Zöphel K, Löck S, Wirth M, Kotzerke J, Krause M, et al. Can local ablative radiotherapy revert castration-resistant prostate cancer to an earlier stage of disease? Eur Urol. 2019;75(4):548-51.

8 Yoshida S, Takahara T, Arita Y, Ishii C, Uchida Y, Nakagawa K, et al. Progressive site-directed therapy for castration-resistant prostate cancer: Localization of the progressive site as a prognostic factor. Int J Radiat Oncol Biol Phys. 2019;105(2):376-81. 